\title{
The aloneness argument: an aspectival response
}

\author{
Joshua R. Sijuwade ${ }^{1}$ (D)
}

Received: 29 September 2021 / Accepted: 3 November 2021

(c) The Author(s), under exclusive licence to The Associates for Philosophy of Religion 2021

\begin{abstract}
This article seeks to provide a response to the Aloneness Argument Against Classical Theism proposed by Joseph C. Schmid and Ryan T. Mullins. This response focuses on showing the unsoundness of the argument once the Doctrine of Divine Simplicity is reformulated within the essentialist aspectival framework provided by the Aspectival Account. Formulating a response to this argument will thus also serve the further purpose of providing an extension of the Aspectival Account and a needed revision of the Doctrine of Divine Simplicity, which can aid others in their quest to further clarify the nature of this doctrine.
\end{abstract}

Keywords Classical Theism · Divine Simplicity $\cdot$ Aspects $\cdot$ Essentialism

\section{Introduction}

In recent analytic philosophy of religion, certain philosophers have sought to raise issues concerning the veracity of Classical Theism-a specific theological trajectory that maintains a strong distinction between God and creation, and includes within it such luminaries as Augustine, Anselm and Aquinas-by proposing various arguments that aim to show the falsity of a specific doctrine: the Doctrine of Divine Simplicity, which underpins the concept of God within this particular trajectory. One important argument: the 'Aloneness Argument Against Classical Theism' (hereafter, Aloneness Argument), has recently been formulated by Joseph C. Schmid and Ryan T. Mullins (2021) in order to demonstrate the falsity of the Doctrine of Divine Simplicity by deducing an internal conflict between it and two other attributes of God that are affirmed by Classical Theism: Divine Creative Freedom and Divine Omniscience. It will be helpful to now unpack their argument and then proceed in the next few sections to formulate a response to it.

The Doctrine of Divine Simplicity (hereafter, DDS), as noted by Schmid and Mullins $(2021,2)$, is best construed as such:

Joshua R. Sijuwade

joshua.sijwade@1st.ac.uk

1 London School of Theology, Northwood, London, UK 
(1) (Divine Simplicity)

There is no metaphysical or physical composition in God, such that:

(i) There is no distinction in God between substance/attribute, essence/existence, form/matter, act/potency, genus/ differentia, agent/action, and essence/accident

(ii) All of God's intrinsic features are identical not only to each other but to God Himself

The central claim made by the DDS is the denial of any form of metaphysical complexity in God. More specifically, it is the denial of the obtaining of a state of affairs in which God possesses a numerically distinct intrinsic feature. In further understanding the nature of this denial, it will be helpful to now follow Schmid and Mullins $(2021,2)$ in defining the notion of an intrinsic feature as follows: a feature of an entity is a 'positive ontological item' of that entity; thus, an intrinsic feature is a feature that characterises an entity solely in virtue of that entity. In contrast, an extrinsic feature is one that characterises an entity in virtue of it standing in a relationship with another entity. According to Schmid and Mullins (2021, 2), intrinsic features are either essential (i.e. features that must be had by an entity), or accidental (i.e. features that can be had or lacked by an entity). ${ }^{1}$

Classical Theists explicitly deny the possession of any accidental intrinsic features by God, primarily due to the fact, as noted by Schmid and Mullins (2021, 5), that an accidental feature is a contingent feature of an entity. And thus, as the DDS requires one to assert the fact of anything intrinsic to God being identical to him, then it would result in God being identical to something contingent, which Schmid and Mullins (2021, 5) say is 'absurd'. However, this absurdity seems to be the conclusion that the Classical Theist must reach if she is to continue to affirm the DDS. That is, the Aloneness Argument seeks to highlight the dilemma that the Classical Theist faces in affirming the veracity of the DDS, and thus, following Schmid and Mullins (2021, 3-6), we can express this argument informally as follows: various theologians and philosophers working within the Classical Theistic trajectory held to the 'aloneness of God'. The aloneness of God is the fact of it being possible that God exists in a 'non-God' world-a world in which there are no other entities with positive 'ontological status'. However, according to the Doctrine of Divine Creative Freedom (a doctrine, as noted by Schmid and Mullins $(2021,2)$ that was widely affirmed within Classical Theism), God is free to create or not create a non-God world, which entails the fact of the creation of the non-God world being a contingent state of affairs - in other words, there is a possible world in which God exists alone, and there are possible worlds in which God exists with non-God things. Thus, given the contingency of creation, any possible world that one picks out would include a contingent truth concerning whether or not God created a non-God world. Moreover, in the worlds in which God exists alone, there will be contingent truths concerning whether God exists alone and contingent truths concerning God's free choice to refrain from creating. Hence, according to Schmid and Mullins (2021, 6), in each

\footnotetext{
1 The nature of the essence/accident distinction assumed in this article will be further elucidated below.
} 
possible world — which would include the actual world — there will be a certain contingent truth concerning God's creative act, or lack thereof.

Now, given the Doctrine of Divine Omniscience (another important doctrinal commitment made by Classical Theists), God is an entity that knows everything that exists, obtains and is true. Thus, as there are contingent truths in every world, it follows from this that, first, God contingently has some knowledge in every world, and, second, this contingent knowledge is either wholly intrinsic, wholly extrinsic, or partly intrinsic and partly extrinsic to God. However, as Schmid and Mullins note (2021, 5-6), in the alone worlds, God would not have this contingent knowledge extrinsically, or partly intrinsically and partly extrinsically, as both of these manners of knowing would require that God stands in some relation to another distinct entity. Yet, in the alone worlds, there would not be any other entities apart from God to fulfil this role. Hence, God's contingent knowledge must be wholly intrinsicGod has this knowledge solely in virtue of himself. Now, this contingent knowledge that is wholly intrinsic to God is either an essential feature of him or an accidental feature. However, it is quite clear that this feature cannot be an essential feature of him, as this would render him as a contingent. Thus, God must have this contingent knowledge accidentally, which entails the fact of it being possible for God to have an accident. Yet, as noted above, if the DDS is, in fact, true, then it is not possible for God to have accidents. Hence, the DDS must thus be false. This informal presentation of the Aloneness Argument can be stated more precisely through the following argument scheme provided by Schmid and Mullins (2021, 6):

(2) (Aloneness Argument) (A1) God's knowledge is either wholly intrinsic to God, wholly extrinsic to God, or intrinsic to God in some respects but extrinsic to God in others

(A2) God's knowledge is (i) wholly extrinsic to God or (ii) intrinsic to God in some respects but extrinsic to God in others only if God doesn't exist alone

(A3) Possibly, God exists alone

(A4) So, possibly, God's knowledge is wholly intrinsic. (A1- A3)

(A5). Necessarily, God contingently has some knowledge

(A6) So, possibly, God contingently has wholly intrinsic knowledge. (A4, A5)

(A7) Whatever is wholly intrinsic to $\mathrm{S}$ is either an essential feature of $\mathrm{S}$ or an accident of $\mathrm{S}$

(A8) Nothing God contingently has can be an essential feature of God

(A9) So, possibly, God has an accident. (A6-A8)

(A10) If DDS is true, it is not possible that God has an accident

(A11) So, DDS is false. (A9, A10)

The conclusion reached by the Aloneness Argument-namely, the falsity of the DDS - results in the veracity of the Classical Theistic framework (which assumes this as an integral doctrine of its framework) being called into question. So, the central question that the Classical Theist must now face is: is the Aloneness Argument indeed a sound argument and thus, for rationality's sake, one should renounce their allegiance to Classical Theism? Now, though I am a proponent of Classical Theism, 
I believe that the Aloneness Argument is indeed sound, and thus gives anyone attracted to the DDS motivation to revise her view-in other words, it is a successful argument against a particular conception of the DDS, resulting in the Classical Theist not being able to consistently maintain this conception in light of the issues raised. So I do believe with Schmid and Mullins $(2021,16)$ that the Aloneness Argument does 'serve as a tool for fresh enquiry about the nature of God and His relation to the created world'. Yet, despite this concession and agreement, it does not mean, as Schmid and Mullins surely believe, that this 'fresh look' should also result in a loosening of one's grip on a strong version of the DDS (through, for example, adopting a weak/non-identity version of the doctrine). As one can indeed affirm a strong version of the DDS without, however, also affirming the classical conception of this doctrine. More specifically, the central focus of this article will be to explicate an account of the DDS that is not plagued by the issues raised by this argument. Yet, to re-iterate the above point, this particular account of the doctrine is not the classical conception of DDS that is expressed through (1) - as it will make some moves, namely the acceptance of accidents in the divine life, that are ruled out by this statement of the doctrine. Nevertheless, this account is one that still upholds a strong version of the DDS, such that it does not deny the numerical identity of God with his attributes, and each of his attributes with one another-in short, a proponent of this account can indeed affirm the statement that 'there is nothing that is in God, that is not God' (Dolezal, 2011, xvi). Thus, the proposed account will indeed be one that a Classical Theist would want to adopt in order to avoid the conclusion of the Aloneness Argument. Since by one employing (a further refined version of) the Aspectival Account of Divine Simplicity (hereafter, Aspectival Account), ${ }^{2}$ one has good reason to doubt (A10) of the Aloneness Argument-namely, the assumption that God cannot have any accidents whatsoever. That is, in other words, this assumption-which we can term the 'Accidents Assumption' - can be challenged by one adopting the Aspectival Account, which will allow a Classical Theist to posit the fact of God bearing accidents (i.e. 'accidental aspects'), yet remaining simple and necessarythus the Accidents Assumption (A10), and the Aloneness Argument that is built on this assumption, being false. Hence, the focus of this article is not to defend the classical conception of the DDS against the Aloneness Argument. Rather, it is to show that the Aloneness Argument is not successful against the strong, yet revised, version of the DDS that is proposed by the Aspectival Account. To put it differently, the focus of this article is to demonstrate the veracity of the following conditional statement: if the Aloneness Argument is successful against the classical conception of the DDS (i.e. (1)), then a Classical Theist should adopt the Aspectival Account in order to ward off this argument and the final conclusion that is entailed by itnamely, the falsity of Classical Theism. The Aloneness Argument is thus assumed to be a successful argument against the classical conception of the DDS, but, as it will

\footnotetext{
2 The Aspectival Account was introduced into the literature by (Sijuwade, 2021), who focused in that article on answering Alvin Plantinga's objections to the cogency of the DDS. This article thus serves as a further extension of this account through the utilisation of the notion of 'essentialism' and the application of this account to another important objection raised against the DDS.
} 
be shown subsequently, it is not a successful argument against the strong version of this doctrine-which is all that is necessary for one to affirm in order to be an adherent of Classical Theism. ${ }^{3}$

Thus, the plan is as follows: in section two ('The Nature of Aspects'), I provide an explication of the notion of an aspect provided by Donald Baxter. Then, in section three ('The Nature of Essentialism'), I provide an explication of the notion of essentialism provided by Kit Fine. After this, in section four ('Aspectival Simplicity'), I focus on applying these two notions to the DDS to show the falsity of the Accidents Assumption, and thus premise (A10) of the Aloneness Argument, which will allow us to affirm the unsoundness of the argument (and provide a means for us to further precisify the DDS). After this section, there will be a final section (Conclusion) summarising the above results and concluding the article.

\section{The nature of aspects}

Donald L.M. Baxter (1999, 2016, 2018a, 2018b) introduced the concept of an 'aspect' into the contemporary metaphysical literature in order to provide a coherent conceptual foundation for the notion of qualitative self-differing (hereafter, self-differing). Self-differing is the qualitative differing of some entity in one way (or respect) from itself in another (Baxter, 1999). To help motivate the existence of aspects within this context, we can consider a case in which an individual is torn about what to do (or how to feel) in a certain situation:

David is an ardent philosophy professor and is also a loving and faithful father of two children, Jacob and Melissa. Now suppose that, firstly, David has an upcoming philosophy conference in which he is the keynote speaker and, due to other work commitments, has not prepared his speech yet. Secondly, suppose that David had previously promised that he would reward his children with a camping trip this upcoming weekend if they achieved $\mathrm{A}^{*}$ grades in their

\footnotetext{
${ }^{3}$ It is important to note that there is a diversity of positions that fall under the category of Classical Theism, as Veli Matti Kärkkäinen $(2017,35)$ writes that there is a 'diversity and plurality of interpretations of God under the umbrella concept of classical theism'. And John W. Cooper (2006, 322), in voicing a similar point writes, 'traditional classical theism is not a single, monolithic position. It has variations and nuances on many issues'. Nevertheless, there is a distinguishing factor between Classical Theism and other models of God, which centres on our understanding of the 'strength' or 'strictness' of the divine attributes, as John C. Peckham (2019, 9-10, emphasis in text) helpfully notes,

Some believe the label classical theism should be reserved for views that affirm a strict conception of the classical divine attributes...A strict classical theist...is one who subscribes to a strong or strict understanding of the divine attributes. Accordingly, the strict classical theist is one who affirms, as a tightly connected package, divine perfection, necessity, pure aseity, utter self-sufficiency, strict simplicity...The italicized modifiers in the previous sentence denote some ways in which strict classical theism affirms these attributes in a strong or strict sense.

This is a vital point. As the adherent of Classical Theism is only required to uphold a strong or strict understanding of the DDS (and the other divine attributes)—rather, than upholding one that has precedent in the classical tradition (such as that expressed in (1)) - in order for them to fall under the umbrella of Classical Theism. One can thus reject the classical conception of DDS, yet affirm a strong (and revised) version of it, and thus still be classed as a Classical Theist.
} 
A-Level results. And, thirdly, suppose that Jacob and Mellissa have both, in fact, recently achieved $A^{*}$ grades in their A-Level results. ${ }^{4}$

In this specific scenario, David is in a situation of self-differing as he knows that he has an important keynote speech that he needs to prepare. David being an ardent philosophy professor results in him wanting to fulfil this commitment and thus complete his speech. So, the following proposition would be true: David 'does not want to take his children on a camping trip this upcoming weekend'. However, having promised his children that he would reward them for their academic achievement, and being a loving and faithful father, he wants to fulfil his promise to them. So, the following conflicting proposition would also be true: David 'wants to take his children on a camping trip this weekend'. David is torn. He is in conflict with himself. He thus differs from himself. David's struggle is between two aspects of him: David insofar as he is a philosopher versus David insofar as he is a father. This, and other cases of internal conflict, are cases of self-differing, where the subjects of what differs are the aspects of the individual that self-differs. Thus, for the case to be one of differing, one aspect must possess a quality that another aspect lacks. And for it to be a case of self-differing, the aspects must be numerically identical with the individual that bears them (Baxter, 2018a, 907). Off of this introduction to the notion of an aspect, we can further elucidate this notion at two levels: the semantic level and the ontological level.

At the semantic level, the aspects in these cases of self-differing, as seen above, are expressed through 'nominal qualifiers' such as 'insofar as' (or 'in some respect' and to a lesser extent 'as' and 'qua') — which serve a special role of referring to aspects, as they are specifically present within self-differing cases, where the same entity can be discernible from itself. Furthermore, following Jason Turner (2014, 227 ), the use of a nominal qualifier in these cases (and other cases like them) can be further precisified via formalisation where one takes ' $a$ ' as a regular term and ' $\varphi(y)$ ' as any formula open in $y$, which allows us to introduce a term to refer to aspects (i.e. an aspect term) written as such: ' $a_{y}[\varphi(y)]$ '. From this semantic basis, we can now progress onto the ontological level, which will allow us to further elucidate the nature of an aspect.

At the ontological level, according to Baxter (2018a, 914), aspects are difficult to distinguish from other entities. ${ }^{5}$ However, we can begin to acquire an understanding of their nature by describing their functional role and the relationship to the

\footnotetext{
4 This example is based on a similar example provided by Baxter (2018a, 901-902). In motivating aspects, Baxter believes that the clearest cases, as in the example in the main text, are those of the internal psychological conflict of a person. However, self-differing, according to Baxter, is not only confined to these psychological conflicts but, as Baxter writes, cases 'of being torn give us the experiences by which we know that there are numerically identical, qualitatively differing aspects. We feel them', (Baxter, 2018b, 104). Thus, at a general level, as we will see, self-differing is present in any case where an entity has a property and lacks it at the same time, in the virtue of playing different roles.

5 As Baxter (2018a, 914) writes, 'aspects should not be confused with Casteneda's guises, or Fine's quaobjects, or other such attenuated entities'.
} 
individuals that bear them. ${ }^{6}$ Primarily, the aspects of an individual function as the particular ways of being of that individual-a particular way or manner in which that individual exists. However, as ways of being of an individual, aspects are not qualities (or properties) as they, themselves, possess qualities (or properties) due to their numerical identity to the individuals that bear them. ${ }^{7}$ Aspects, however, do not possess all of the qualities that the particular individuals that they are aspects have. Moreover, in a similar manner to their bearers, they are particular entities-rather than universals-through Leibniz's Law failing to hold for them. ${ }^{8}$ Secondly, despite the numerical identity between individuals and their aspects, aspects are not 'complete individuals', due to the fact that complete individuals are entities that can exist independently. Instead, according to Baxter (2018a, 916), aspects are 'incomplete entities' due to them 'having fewer properties than it takes to exist on one's own'. Aspects are thus incomplete in the sense of them being dependent upon the complete individuals that they are numerically identical to. The nature of a complete individual determines the aspects that they have, in that they depend entirely upon how that individual entity is - once we have the individual, we also have its ways of being (Giannotti, 2019, 2). Thirdly, aspects are not mereological parts of the individuals that they are aspects of, as, again, they are numerically identical to, rather than a 'part' of, these individuals (Baxter, 1999, 2). Lastly, aspects are not mental abstractions. That is, even though a complete individual's aspects are abstract entities (through them failing to exhaust the content or plime that they are aspects of), that can be considered by means of abstraction-where one abstracts a way that an individual is - it is important to note, as Baxter $(2016,104)$ writes, that the difference between a complete individual and their aspects is 'a less-than-numerical distinction but more than a mere distinction of reason'. Baxter terms this distinction an aspectival distinction, which results in the aspects of an individual only ever being two (or more) in a 'loose' sense when they are counted based on qualitative distinction. However, in a 'strict' sense, when the aspects are counted based on a numerical distinction, they are only ever one. Thus, aspects, as Baxter notes, provide a 'complexity to the simple, i.e., a qualitative complexity to the quantitatively simple' (Baxter, 2016, 178).

Taking this explanation of the semantic and ontological features of aspects into account, for further clarity, we can construe the concept of an aspect more precisely as follows:

\footnotetext{
${ }^{6}$ This functional role fulfilled by an aspect is similar to that of 'mode', which has recently been re-introducedinto the literature Jonathan Lowe (2006, 23-24), and John Heil (2012, 3-4). However, the central differencebetween an aspect and a mode is that the former, and not the latter, is numerically identical with the individualthat bears it.

${ }^{7}$ In reference to aspects, there will be an interchanging of the term 'qualities' with the term 'properties'. However, the former term is preferable over the latter term, as it helps us to ward of mistaking the entities that are born by aspects to be further entities that are ontologically different from them.

${ }^{8}$ More on this below.
} 
(3) (Aspect) (a) An aspect is a qualitatively differing, incomplete abstract particular entity that is numerically identical to the complete individual that bears it (and any other aspect possessed by that individual)

(b) It functions as a particular way that a complete individual is and is determined by that individual's nature

(c) It is expressed through a nominal qualifier such as 'insofar as', which, at a precise level, can be captured through the use of an aspect term (such as $a_{y}[\varphi(y)]$ )

(d) It is distinguishable through an aspectival distinction, rather than a numerical or conceptual distinction

From this basic construal of an aspect, we can now return to our example of selfdiffering and re-construe the notion of self-differing to be that of the qualitative differing of numerically identical aspects possessed by an individual (Baxter, 2018b, 92). So, for example, 'David insofar as he is a philosopher' refers to one, numerically identical aspect of David and 'David insofar as he is a father' refers to another, numerically identical aspect of him. Aspects can thus differ in their qualities without the resultant differences indicating numerically distinct individuals (Baxter, 2016, 175). More fully, we can apply some aspect terms to our self-differing example, where one aspect term of David would be: $\operatorname{David}_{y}[y$ is a father $]$, which is a name for 'David insofar as he is a father'. And another aspect term of David would be $\operatorname{David}_{y}[y$ is a philosopher $]$ which is a name for 'David insofar he is a philosopher'. Thus, re-construing the above situation as such:

(4)

David $_{\mathrm{y}}[\mathrm{y}$ is a philosopher] does not want to take his children on a camping trip this weekend

and

(5)

$\sim$ David $_{\mathrm{y}}[\mathrm{y}$ is a father] does not want to take his children on a camping trip this weekend

It would seem as if one is affirming a contradiction. However, through the use of nominal qualifiers such as 'insofar as' (i.e. formally $a_{y}[\varphi(y)]$ ), it removes any explicit contradiction, as the above case does not say that it is David, unqualified, that does and does not want to take his children on a camping trip this weekend. Nor does it say that David, in one 'part', does not want to take his children on a camping trip this weekend. Either of those, as Baxter (2018b, 908) notes, would

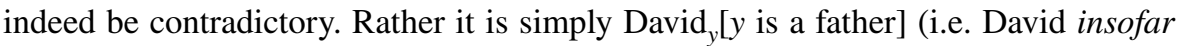
as he is a father) who wants to take his children on a camping trip this weekend, and $\operatorname{David}_{y}[y$ is a philosopher] (i.e. David insofar he is a philosopher) who does not want to take his children on a camping trip this weekend. So, at a 'coarse-grained' level, in our example, we have David being in a self-differing situation in which he has two aspects that qualitatively differ: $\operatorname{David}_{y}[y$ is philosopher $]$ and $\operatorname{David}_{y}[y$ is a father]. However, at a more 'fine-grained' level, what we do in fact have is a qualitative difference between the sub-aspects of David, where a sub-aspect of an entity can be construed formally as follows: 
(6) (Sub-Aspect)

$(\exists x)(\exists z)\left(x_{y}[\varphi(y)] z_{y}[\varphi(y)]\right)$

Informally:

Some $z$ is an aspect of an aspect $x$

Specifically, the conflict that we have in this case is not so much between $\operatorname{David}_{y}[y$ is a philosopher] and $\operatorname{David}_{y}[y$ is a father], but the sub-aspects of these aspects: David insofar as he is a philosopher (aspect) insofar as he is the keynote speaker (sub-aspect)—which can be written as the aspect term: $\operatorname{David}_{y}[y$ is a keynote]. And David insofar as he is a father (aspect) insofar as he made a promise (sub-aspect) which can be written as the aspect term: $\operatorname{David}_{y}[y$ is promiser]. It is these entities that qualitatively differ, and not the aspects of Davis per se, as it is specifically David in fulfilment of his role as a philosopher who fulfils the role of the 'keynote' and thus, given the latter role, he does not want to take his children on the camping trip. And it is David in fulfilment of his role as a father who fulfils the role of 'promiser' (to his children), and thus, given the fulfilment of this role, he does want to take his children on the camping trip. Sub-aspects, and not just the aspects of the individual under question, thus play an important role in this case and others. For reasons of brevity, however, we will continue at a more 'coarse grained' level to refer to the aspects (and not the sub-aspects) of David as playing a role in this self-differing case-with the notion of a sub-aspect being re-introduced in the next section. Thus, what we have with the aspects (and the sub-aspects) of an individual is that of the negation, as Baxter $(2016,104)$ writes, being internal 'that is, has short-scope relative to the nominal qualifier and so there is no contradiction'. Thus, it is the aspects of David that has the conflicting qualities noted above, but not David (unqualified). That is, one can block the secundum quid ad simpliciter inference, which, following Baxter (2018a, 913), can be written formally as such:

\begin{tabular}{ll}
\hline (7) (Block) & $\sim(\forall x)\left(F\left(x_{y}[\varphi(y)]\right) \rightarrow F x\right)$ \\
Informally: & It doesn't follow from the fact that an aspect of a complete individual $\mathrm{x}$ is $\mathrm{F}$ that $\mathrm{x}$ is $\mathrm{F}$
\end{tabular}

So, according to Baxter (2018a, 913), by the above being true, an individual insofar as they are a particular way bearing a particular quality does not entail that the individual unqualified bears that same quality. Thus, in our case, supposing David insofar as he is a philosopher does not want to go on a camping trip, it also does not follow that David does not want to go on a camping trip - as David might in fact mostly want to go on the camping trip rather than not, so that 'David does want to go on a camping trip' is what is overall true. Yet, $\operatorname{David}_{y}[y$ is a philosopher $]$ and $\operatorname{David}_{y}[y$ is a father $]$-as aspects of David_are identical to him. Thus, as Baxter (2018a, 911) notes, the following principle holds within an aspectival context:

$\begin{array}{ll}\text { (8) (Aspect Identity) } & (\forall x)\left(x=x_{y}[\varphi(y)] \rightarrow(\exists z)\left(x_{y}[\varphi(y)]=z\right)\right) \\ \text { Informally: } & \text { Every aspect is numerically identical with a complete individual } x\end{array}$


In reality, David is $\operatorname{David}_{y}\left[y\right.$ is a philosopher], and David is $\operatorname{David}_{y}[y$ is a father] David insofar as he is a particular way (i.e. as philosopher or father) is still David. ${ }^{9}$ Moreover, taking into account the characteristics of the numerical identity relation-specifically the transitivity of identity-will result in:

which is that of David's aspects each being numerically identical to one another. Thus, in this context, the same thing can be abstractedly considered in two ways, and in this discernment, it can differ from itself whilst still being that same thing. David is numerically identical to the two above aspects (and a near-infinite amount other aspects), and these aspects are all numerically identical to each other. The same individual can possess qualitatively differing aspects that are nevertheless numerically identical to the individual that bears them and also with each other.

This all seems to be conceptually coherent; however, a pertinent issue appears to be in sight-namely, the potential transgression of Leibniz's Law. Leibniz's Law (the Indiscernibility of Identicals) can be construed formally as such:

(10) (Leibniz's Law) $\forall x \forall y(x=y \rightarrow(\varphi(x) \leftrightarrow \varphi(y))$

Informally: $\quad$ For any things $x$ and $y$, if $x$ is numerically identical with $y$, then for any quality $F$, $F$ is had by $x$ if and only if $F$ is had by $y$

At a prima facie level, Leibniz's Law seems to be transgressed within an aspectival framework, as the existence of aspects allows for there to be numerically identical entities that do not share the same qualities. Any violation of Leibniz's Law will certainly be problematic for most individuals. However, once this issue is further investigated, we can, in fact, see that there is no violation of Leibniz's Law within an aspectival framework as, according to Baxter (2016, 172), aspects allow 'contradictories to be predicated of the same thing in a way that Leibniz's Law is silent about'. We can begin to notice this 'silence' by asking the question of why Leibniz's Law should be taken to apply to all entities, without restriction? Baxter sees that the issue might revolve around the frequently raised worry, ${ }^{10}$ that a relation that is not characterised by Leibniz's Law is not identity. ${ }^{11}$ However, Baxter (2018a, 908) sees that the only reason for this attitude is that the principle seems to express the truth that no entity both possesses and lacks a property - that contradictions cannot exist in reality. Thus, as Baxter (2018a, 907) writes, 'It may seem that the original Indiscernibility of Identicals [Leibniz's Law] is just another way of saying that nothing both has and lacks a property, which is just another way of saying that no

\footnotetext{
${ }^{9}$ This identity and conception of the nature of an aspect would also apply to the sub-aspects of an individual.

${ }^{10}$ As Ted Sider $(2007,58)$ notes (in a related mereological context), 'Defenders of strong composition as identity must accept this version of Leibniz's Law; to deny it would arouse suspicion that their use of 'is identical to' does not really express identity'.

${ }^{11}$ One might still comment that it is inconceivable to define numerical identity without utilising Leibniz's Law, and thus Baxter's approach should be rejected. However, Baxter notes that he is not defining identity; but instead is taking it as primitive.
} 
contradictions are true'. It thus seems that individuals regularly accord Leibniz's Law (the Indiscernibility of Identicals) the same unassailable status that is regularly given to the Principle of Non-Contradiction. However, following Aristotle, Baxter (2018a, 908) sees that what is central to the latter principle is solely that of nothing both possessing and lacking a property in the same respect at the same time. Thus, this formulation leaves room to manoeuvre as it opens up the possibility that, as Baxter $(2018 \mathrm{~b}, 105)$ writes, 'something in one respect has a property that it in another respect lacks'. However, that claim is not contradictory, as a contradictory claim here would be for one to say that some individual in one respect possesses a property that in no respect it possesses. Baxter's non-contradictory claim is thus simply that something in one respect is numerically identical with itself in another respect. ${ }^{12}$ Thus, based on this claim, some numerically identical things can qualitatively differ without an entailment of a contradiction. Baxter (2018a, 907) thus believes that we lack any substantial reason to believe that Leibniz's Law applies to every entity without question, and states that 'Leibniz's Law should not be thought of as applying absolutely generally to anything that can be talked about; the argument that it must apply so generally, fails'.

Rather it is important to consider the domain of quantification for Leibniz's Law. That is, according to Baxter, Leibniz's Law solely applies to individuals (i.e. complete/independent entities) and thus does not generalise over to aspects (i.e. incomplete/dependent entities). The non-contradictory internal negation in specific selfdiffering claims, such as David's above, seems to suggest that Leibniz's Law does not apply to aspects. Thus, there are certain cases in which identicals are discernible, yet do not falsify the principle-namely when an individual possesses aspects that are numerically identical to it (and each other). The same thing cannot be true and false of the same individual, in the same respect, without entailing a contradiction (Baxter, 2018a, 908). Yet, phrases such as 'David insofar as he is a father' refer to aspects, which are incomplete entities, and not the complete individual that the aspect is numerically identical with. Thus, as Baxter (2018a, 907) notes, it is vital that one is sensitive to 'aspectival reference', which refers to aspects and is distinguishable from singular reference, which refers to complete entities. Singular reference, according to Baxter, is not sensitive to the aspectival distinction, whilst the former is. And once we are sensitive to this distinction, we can realise that the domain of quantification for Leibniz's Law, in its original sense, as Baxter (2018b, 104) writes, 'includes all the complete entities, but does not include the incomplete entities numerically identical to some of them'. Thus, it follows that Leibniz's Law does not preclude the numerically identical aspects of an individual from being qualitatively different from each other and the individual themselves. ${ }^{13}$ Assuming the reality of aspects thus does not lead to a complete denial of Leibniz's Law.

\footnotetext{
12 A single individual differs from itself by having two or more aspects.

13 Baxter $(2018$ a, 909) sees Leibniz's Law as being closely related to the further principle that co-referential terms are substitutable salva veritate. However, he notes that this specific principle concerns only singular reference, and thus the substitution of expressions only refers to single individuals. One would thus need to provide an argument for why it should be generalised to aspects.
} 
Instead, there is only a denial of an unrestricted understanding of Leibniz's Law that includes all complete and incomplete entities within its domain. More can indeed be said here. However, for the task at hand, we can conclude that Leibniz's Law does not apply to aspects, and thus it is coherent to posit the existence of qualitatively differing, yet numerically identical aspects. We can now turn our attention to the notion of essentialism and see how this can be utilised in further precisifying the nature of aspects.

\section{The nature of essentialism}

Kit Fine (1994a, 1994b, 1995) re-introduced into contemporary metaphysics a 'nonmodal' (or, neo-Aristotelian) characterisation of essence. The common approach to essence in contemporary metaphysics, prior to the pioneering work of Fine, was a 'modal' characterisation of essence that conceives of an essence as a modal notion-and thus essential truths are a subset of the modal truths. ${ }^{14}$

Against this latter approach, however, Fine has argued that the modal characterisation account commits one to accept certain predications that say nothing about what it is to be the entity in question. Yet, as essentialist predications, according to Fine (1994a, 4-5), intuitively should do this, the properties expressed by these predications that are in fact irrelevant to the nature of a given entity can in no way be essential to it. In short, one cannot thus reduce essence to any modal notion. ${ }^{15}$ Given this, Fine believes that one must instead proceed to detail the nature of essence through an alternative, non-modal approach-focused on the further notion of a real definition. ${ }^{16}$ More specifically, non-modal essentialism conceives of an essence as

\footnotetext{
${ }_{14}$ This modal characterisation is also the one followed by Schmid and Mullins $(2021,2)$ in the Aloneness Argument.

15 The primary method that Fine (1994a, 3-5) followed in showing the failings of the modal characterisation was by adducing certain counterexamples that emphasised the fact that essentialist claims are intuitively tied to what an entity is, and thus the modal characterisation of essences fails to provide a notion that is, in fact, co-extensional with this intuitive view. The most famous of these counterexamples centres on Socrates and the singleton set \{Socrates\} that contains him. For a detailed unpacking of this counterexample and other similar counterexamples, see (Fine, 1994a, 3-5).

${ }^{16}$ A question that one can ask-and one that I would like to thank an anonymous reviewer for raising - is that of why one should adopt Fine's approach when a simpler account of essence is at handspecifically, an 'intrinsicality' account, which can be stated as follows: $a$ is essentially $\mathrm{F}$ iff necessarily if $a$ exists then $a$ is intrinsically $\mathrm{F}$ (i.e. the essential properties of a thing are the intrinsic properties that it cannot fail to have). This account handles Fine's counterexamples to modal essentialism (e.g. being a member of singleton Socrates is not intrinsic to Socrates; singleton Socrates is Socrates 'wearing braces' etc.). However, despite the ability for this account to ward off the issues faced by the modal characterisation account, one should indeed favour Fine's account for two reasons: first, the intrinsic/extrinsic property divide is notoriously difficult to demarcate-and thus one is utilising an unclear notion (i.e. intrinsicality) to provide clarity to an unclear notion (i.e. essentiality). Second, the former, and not the latter, is able to rightly class extrinsic properties (e.g. Socrates' origination from Sophroniscus and Phaenarete), as well as intrinsic properties (e.g. Socrates being human), as essential properties of an entity. In other words, the intrinsicality account seems to be unclear (as the notion of the intrinsicality is itself unclear) and too strong (as there are indeed essential extrinsic properties) and thus one has good reason to proceed to utilise Fine's non-modal account, as it provides a clearer and more flexible approach for clarifying the issue at hand.
} 
one that functions as the definition of the entity in question. This identification of an essence with a definition is expressed by Fine (1994a, 3) when he writes, 'my overall position is the reverse of the usual one. It sees real definition rather than de re modality as central to our understanding of the concept'. And thus, as he further writes, 'just as we may define a word, or say what it means, so we may define an object, or say what it is' (Fine, 1994a, 2). Essence is thus taken by Fine to be ontologically equivalent to a linguistic definition. That is, in a similar manner to a linguistic definition - which states what a certain term means - an essence acts as a real definition of an entity-it reveals and explains the essence of an entity (without being a distinct entity from that essence). In short, it states what that object is. Real definitions thus act in a manner as explanatory principles, in that they tell us, in the most perspicuous manner, what the entity is, as Fine (1994a, 3) expresses this in writing that.

[T] he traditional assimilation of essence to definition is better suited to the task of explaining what essence is. It may not provide us with an analysis of the concept, but it does provide us with a good model of how the concept works.

Consequently, Fine sees a definitional characterisation of essence as the one that is needed for this task, as the essence of an entity is those propositions that are part of the entity's 'definition' and thus this approach, unlike the modal approach, enables only relevant propositions to be included within the essence of an individual (Fine, 1995). Taking these things into account, we can construe the notion of an essence, identified as the real definition of an entity, more precisely as follows:

\section{(11) (Essence) The essence (or real definition) of $x$ is the collection of all propositions that are true in virtue of the nature of $x$}

Importantly, Fine (1994b, 54-55) sees that the 'true in virtue of the nature of' locution signifies an unanalysed relation between a proposition and an entity-where a proposition bears this relation to an entity when that proposition is true because of the entity having the nature that it does. A nature within the non-modal essentialist framework under question is the collection of the properties that are possessed essentially by that entity - they are properties that make the entity be the entity that it is. Given this construal of an essence, we can re-construe the essential/accidental distinction as follows: first, for essential properties, we can conceive of them formally as follows (with $\mathbf{E}$ standing for 'essential property' and $\mathbf{M}$ standing for 'making an entity what it is'):

\begin{tabular}{ll}
\hline $\mathbf{E}(F, x) \rightarrow \mathbf{M}(F, x)$ \\
Informally & If $F$ is an essential property of $x$, then $F$ is a property that makes $x$ what it is. \\
\hline
\end{tabular}

Second, for accidental properties, we can conceive of them formally as such:

(13) (Accidental) $\quad \sim \mathbf{E}(F, x) \rightarrow \sim \mathbf{M}(F, x)$

Informally: $\quad$ If $F$ is an accidental property of $x$, then $F$ is a property that does not make $x$ what it is 
So, in utilising the distinctions that are available within this non-modal essentialist framework, we can again focus on David from our previous section, who is a human person that fulfils the role of being a philosopher and father (amongst other things). We can state these distinctions in David's case as such: (Table 1).

David has an essence: a human essence, which is identified as a real definition that expresses what he is - namely, that of him being a human. More specifically, the essence (or real definition) of David is the collection of propositions that are true in virtue of the human nature of David. The human nature that is had by David would itself be a collection that is made of the properties that are possessed essentially by David - in that they are properties that make David be the entity that he is: human. And thus, in assuming an Aristotelian view of humanity, we can take these essential properties to be such things as rational animality, moral awareness and freedom of the will. David is essentially a human; however, he is also a philosopher and a father, and thus has the properties of being a philosopher and being a father. However, as these latter properties do not make David what he is - they do not make him human-they are accidental properties of David, and thus can be lacked by him, without him ceasing to be what he is.

For heuristic purposes, we can illustrate the various distinctions made within the non-modal essentialist framework in this specific example as follows (with 'Philosophy' standing for 'David's role as a philosopher', 'Father' standing for 'David's role as a Father', 'Rationality' standing for 'rational animality', 'Moral A' standing for 'moral awareness', 'Freedom' standing for 'freedom of choice', 'TIVO' standing for 'true in virtue of', 'PMUB' standing for 'partly made up by') (Fig. 1):

In this illustration, we see the essential properties of David being connected to his nature and thus his essence. In contrast, the accidental properties of David do not have a connection to his nature and thus his essence. In other words, it is the essential properties of David, and not his accidental properties, that play a role in defining him as he is-through making up David's nature, which his essence (or real definition) is true in virtue of. Taking this all into account, from our unpacking of the nonmodal conception of essence provided by Fine, and the notion of an aspect provided by Baxter in the previous section, we can now finally bring these notions together, which will help us to deal with the Aloneness Argument.

\section{Aspectival simplicity: an essentialist extension}

God is construed within the Aspectival Account as an entity that is numerically identical to an omnipotence module trope (hereafter, omnipotence-trope or simply Omnipotence). A module trope is an abstract particular nature of a modular kind. ${ }^{17}$ In briefly unpacking this within a theistic context, God is, first, abstract in the sense of him having the trait of being 'less than the including whole'-in a

\footnotetext{
17 The following is a very brief statement of the nature of a module trope, as elucidated within a theistic context. For a further explanation of the nature of module trope (and that of a modifier trope) and a further explanation for why God must indeed be conceptualised as this type of entity, see (Sijuwade, 2021).
} 


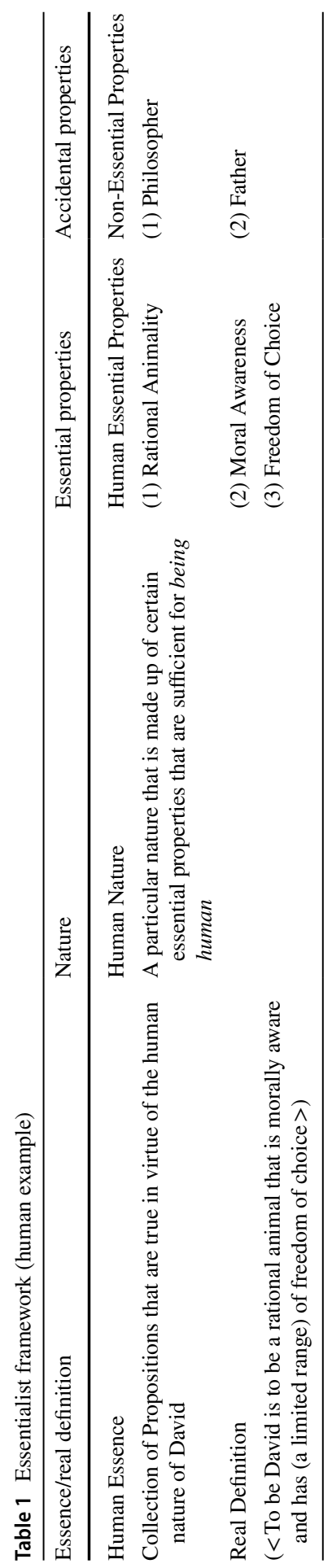




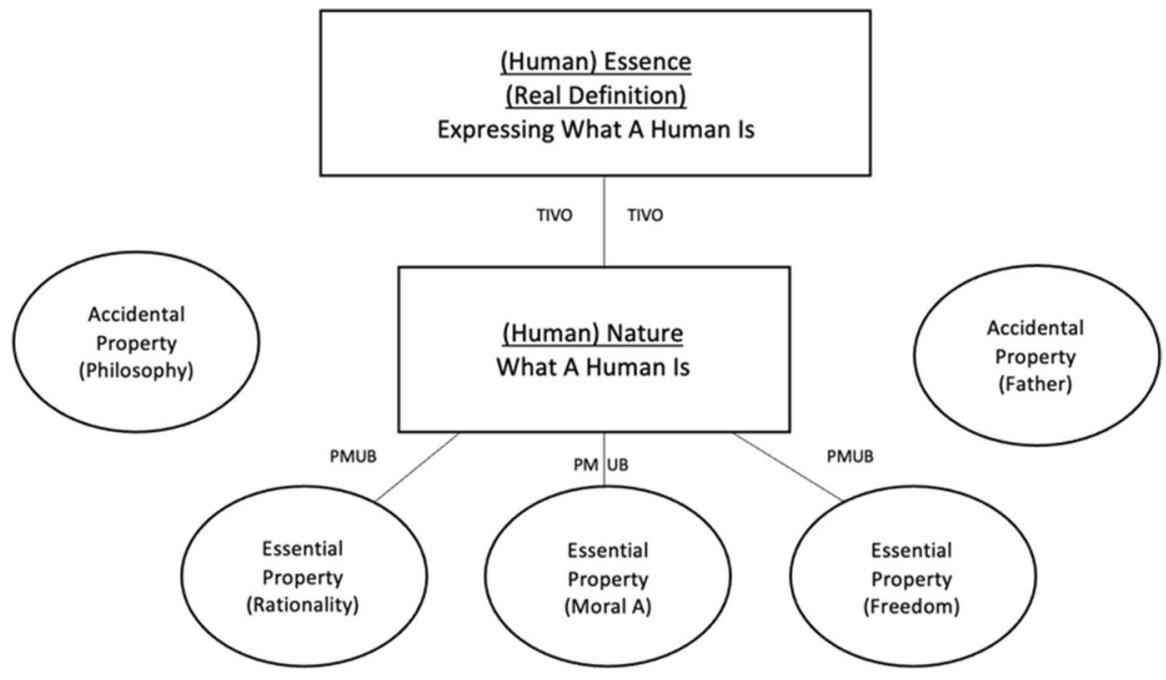

Fig. 1 Essentialist framework (human example)

Christian theistic context, God does not exhaust his 'content' or 'plime' (or is less than his 'content' or 'plime') — identified as the Trinity — as his content or plime also includes the possibility of other tropes being collocated with him (i.e. the Son and the Spirit), which results in him not exhausting either of these things-in short, wherever God is located there are other tropes that are located there with him. Second, God is particular by him failing to abide by Leibniz's Law (the Identity of Indiscernibles) — as again within a Christian theistic context - there is the possibility of the existence of entities-duplicates, identified as the Son and the Spirit-that are exactly similar in their intrinsic properties (i.e. their nature) to him, yet are numerically distinct from him. ${ }^{18}$ Third, God is identical to his qualitative nature-he is the specific character that he has, which is that of him being omnipotent. God's nature is thus intrinsic to him, not in the sense of him possessing a further intrinsic 'property', but simply that of him being numerically identical to this nature. Fourth, God is a trope of a modular kind, which is that of him being a maximally-thinly charactered object-a property in an analogous sense (i.e. a property*) — that is self-exemplifying and - in assuming Christian Theism again - serves the role of bestowing this characteristic upon the Trinity which he constitutes. Moreover, since God is a trope of a modular kind, he plays a direct role in causation and is thus a basic term of a causal relation. Thus, as God is numerically identical to an omnipotence-trope, he is a module trope that has the ability to perform any logically possible action. God is thus an omnipotence-trope. However, instead of this omnipotence-trope entailing the possession of the further properties of omniscience, omnipresence, perfect

\footnotetext{
18 Leibniz's Law was previously conceived of here as the principle of the indiscernibility of identicals. However, now we are conceiving of it in this case as its converse-the principle of the identity of indiscernibles, which can be stated formally as such: $\forall \varphi(\varphi(x) \leftrightarrow \varphi(y) \rightarrow x=y)$.
} 
freedom and perfect goodness (as is regularly taken to be so), ${ }^{19}$ we can now 'convert' these properties into aspects, which will also result in the entailment relation being converted into a relation of numerical identity. So, in mapping out this conversion process, we can illustrate this as such (Fig. 2):

Given these conversions, we can now further understand the nature of these 'aspects of omnipotence' by focusing on their functional role and the relationship that they have to the omnipotence-trope, which allows us to say that they are not properties, complete entities, or mereological parts. Rather, they are incomplete abstract particular entities that are numerically identical to a specific complete individual and function as his ways of being. More fully, each of the aspects of omnipotence is numerically identical to the omnipotence-trope, yet they do not possess the same characteristics as it - they are not the ability to perform any logically possible action. Lacking this characteristic, the aspects of omnipotence are thus incomplete entities, in that they are dependent on the omnipotence-trope, which exists as a complete entity (i.e. an independently existing entity). These aspects of omnipotence do not exhaust the content or plime that they are aspects of (i.e. they each do not exhaust the omnipotence-trope), and they each function as ways that the omnipotence-trope exists, which we can consider through a process of abstraction. This aspectival construal of the divine properties thus allows us to re-define the traditional set of divine properties in Table 2 as $\operatorname{such}^{20}$ :

At a specific level, these aspects of omnipotence are focused on the different particular ways in which the omnipotence-trope is. That is, by this module trope having (or, more specifically, being) the singular-character of omnipotence, it would exist in a particular manner and have certain limitless abilities that enable it to fulfil different roles. This functional role fulfilled by the omnipotence-trope allows one to establish an aspectival distinction that takes these ways to be aspects of this specific trope. Therefore, as was seen with our previous example, we have a case of self-differing here. The subjects of this differing would be the aspects of the omnipotencetrope, with each aspect possessing a 'quality' that each of the other aspects lacks. ${ }^{21}$ For instance, focusing on the Omniscient-Aspect and the Freedom-Aspect, we have the following examples:
(14) Omnipotence ${ }_{y}[y$ is knowledge $]$ enables its bearer to know whether it snowed in New York on Janu- ary $1^{\text {st }} 2$ A.D
(15) Omnipotence ${ }_{y}[y$ is freedom $]$ enables its bearer to know whether it snowed in New York on Janu- ary $1^{\text {st }} 2$ A.D

\footnotetext{
${ }^{19}$ For a detailed explanation of why there is this entailment of the other divine properties from omnipotence, see (Swinburne, 2016, 174-75). Furthermore, the construal of omnipotence above is a basic construal provided by (Swinburne, 2010, 8), which is subject to certain counterexamples (such as the 'McEar' objection). For these counterexamples and a more refined definition of omnipotence that does not face these counterexamples, see (Swinburne, 2016, 150-74).

20 The traditional set of divine properties would include more than what is included here. However, for brevity's sake, we will focus on these specific five properties. Furthermore, this specific set of properties and their definitions are derived from the work (Swinburne, 2016).

21 The qualities would be 'sub-aspects' of the aspects under question-more on the nature of sub-aspects within a theistic context below.
} 
And, for the Omnipresent-Aspect and the Goodness-Aspect, we also have the following examples:

(16) Omnipotence $[$ [y is presence $]$ enables its bearer to be cognizant of, and causally active at, the Galactic Center

(17) Omnipotence ${ }_{y}[y$ is goodness $]$ enables its bearer to be cognizant of, and causally active at, the Galactic Center

In these examples, we do not have a case of internal conflict, as in the example of David above; however, it is a case of differing, by there being a qualitative difference between the aspects of the omnipotence-trope. And, importantly, it is a case of selfdiffering, as the aspects are numerically identical to the omnipotence-trope itself. This is certainly the case, as from the position that was reached at the beginning of this section of God being numerically identical to the omnipotence-trope:

we can now, within this aspectival framework, proceed to posit a numerical identity between the omnipotence-trope and the various aspects of omnipotence:

(19) Omnipotence $=$ Omnipotence $_{y}[y$ is knowledge $]$; Omnipotence ${ }_{y}[y$ is presence $]$; Omnipotence $y[y$ is freedom]; Omnipotence ${ }_{y}[y$ is goodness]

Omnipotence insofar as it is a certain way (e.g. an omniscient way, an omnipresent way etc.) is still Omnipotence, which is still, at the bottom level, God. Yet, due to the formal characteristics of the numerical identity relation-namely, the transitivity of identity - each of the aspects of omnipotence is also numerically identical to each of the other aspects:

Within an aspectival context, the same thing: the omnipotence-trope, which is numerically identical to God, is discerned in multiple ways without absurdity. More specifically, within this aspectival framework, there is one property*, the omnipotence-trope, that is identical to multiple aspects, which are, in turn, identical to one another. In short, God is the omnipotence-trope, the omnipotence-trope $i s$ the qualitatively differing aspects of omnipotence, and the qualitatively differing aspects of omnipotence are one another. The traditional understanding of the possession of 'many qualities' by God is thus, in fact, the possession of many qualitatively differing, yet numerically identical aspects. The aspects of omnipotence provide a certain 'complexity to the simple'-a qualitative complexity to the quantitatively simple omnipotence-trope which God is. Thus, by utilising an aspectival distinction here, in a 'loose' sense, focused on qualitative distinctiveness, we can indeed count a multiplicity of aspects within God. Yet, in a strict sense, focused on numerical 

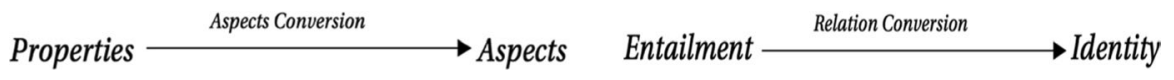

Fig. 2 Aspectival and relation conversions

distinctiveness, there is solely one self-same property*, the omnipotence-trope, which is differently considered. We can now illustrate the position reached here as such (with the double-headed arrows representing an identity relation) (Fig. 3):

Turning our attention now onto non-modal essentialism, an essence, as previously noted, focuses on stating what it is to be a certain thing through the notion of a real definition - a collection of all the propositions that are true in virtue of the nature of an entity. In the aspectival framework developed here, we retain this conception of essence. However, by us converting God's properties to aspects, we now take the nature of God to be construed as the collection of the aspects that are possessed essentially by God-they are the aspects that make God the entity that he is. This allows us to now conceive of the essential/accidental distinction as follows: first, for essential aspects, we can construe them formally as follows (with $\mathbf{E}$ standing for 'essential aspect' and $\mathbf{M}$ standing for 'making an entity what it is'):

(23) $\left(\right.$ Essential*$\left.^{*}\right)$

Informally:
$\mathbf{E}(F, x) \rightarrow \mathbf{M}(F, x)$

If $F$ is an essential aspect of $x$, then $F$ is an aspect that makes $x$ what it is

Second, for accidental aspects we can construe them formally as such:

\begin{tabular}{ll} 
(24) (Accidental $*)$ & $\sim \mathbf{E}(F, x) \rightarrow \sim \mathbf{M}(F, x)$ \\
Informally: & If $F$ is an accidental aspect of $x$, then $F$ is an aspect that does not make $x$ what it is \\
\hline
\end{tabular}

So, within a theistic context, we can apply these various distinctions to the case of God in Table 3 as follows:

God, as with other entities, has an essence: a divine essence, which is identified as a real definition that expresses what he is-namely, that of him being divine. The essence (or real definition) of God is the collection of propositions that are true in virtue of the divine nature of God. The divine nature that is 'had' by God would itself be a collection that is made up of the aspects that are borne essentially by God-in that they are qualitatively differing, yet numerically identical, aspects that make God be the entity that he is: divine. And thus, taking into account the aspects of omnipotence introduced previously, these would be the Omniscience-Aspect, Omnipresence-Aspect, Perfect Freedom-Aspect and the Perfect-Goodness-Aspect. God would thus bear a number of essential aspects that he must have in order to be God. For example, focusing on the relationship between the Omniscience-Aspect and the characteristic of being omnipotent, for God to be an omnipotence-tropethat is him having the ability to perform any logically possible action-then he must, at the minimum, possess knowledge of what occurred in the past (and what is occurring now in the present) in order for him to know of (and believe no false propositions about) what actions are logically possible for him to perform at any given 


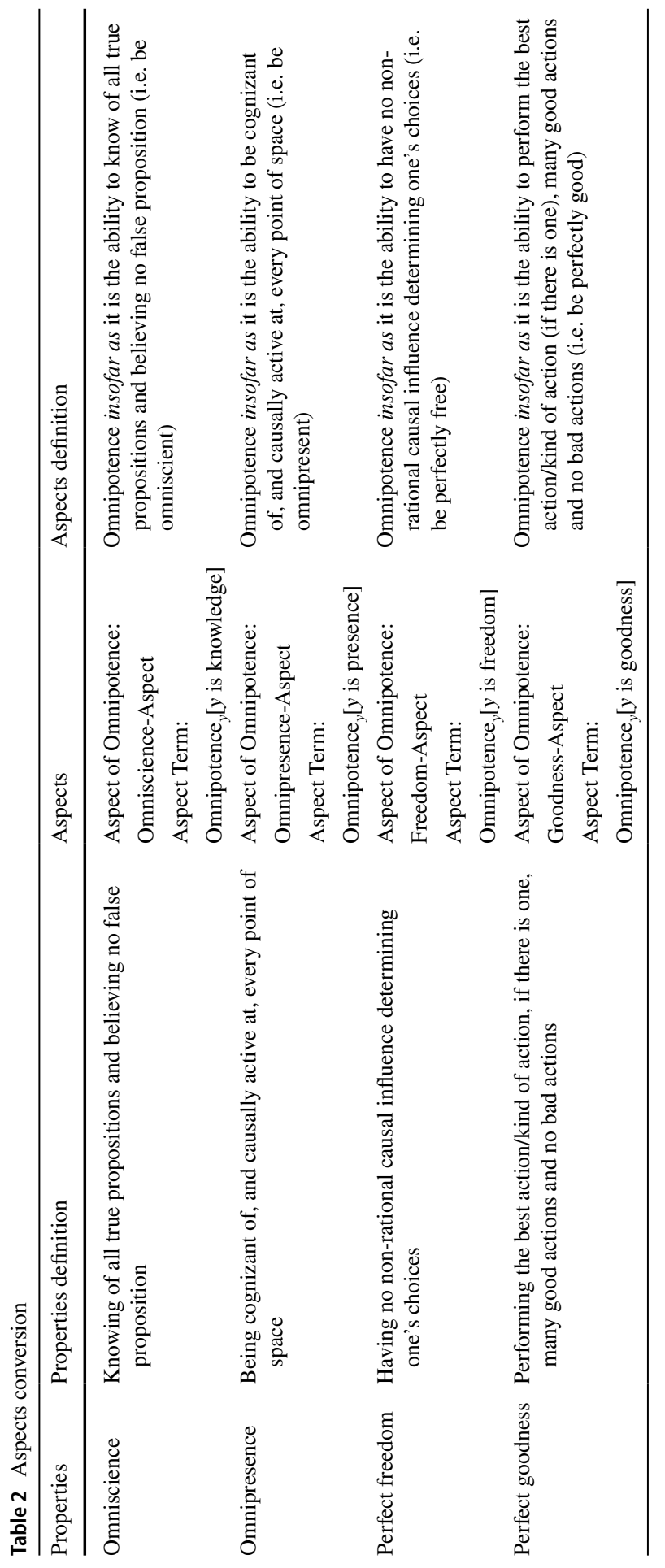




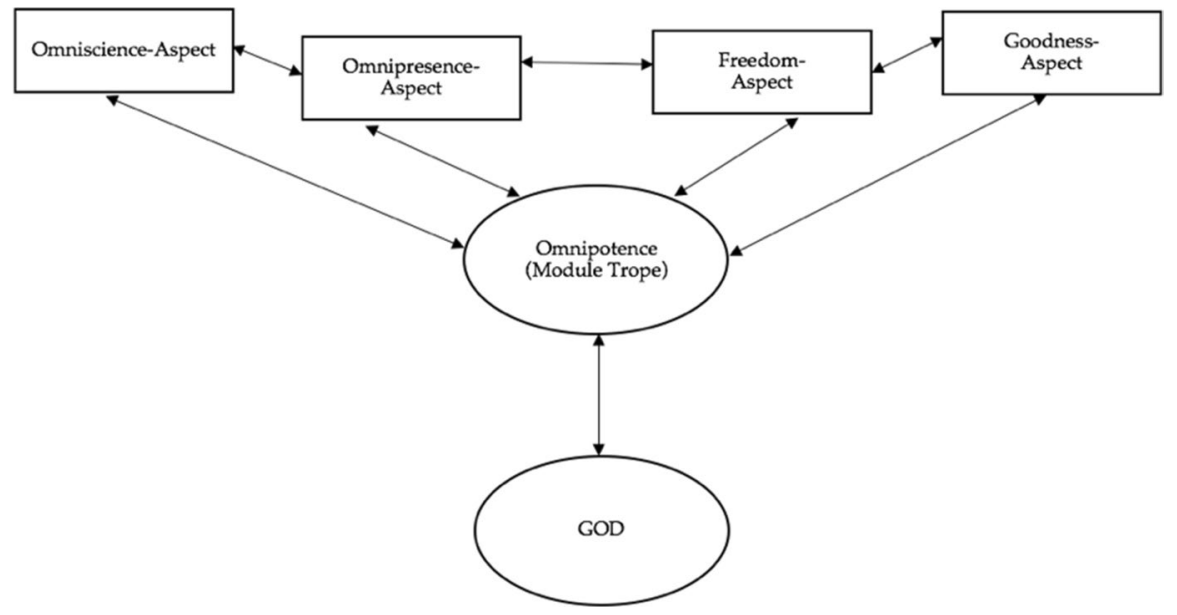

Fig. 3 Aspectival simplicity

point in time. Thus, to be what God is - namely, an omnipotence-trope-God must also have the ability to know the truth of all propositions (and believing no false proposition) - in short, God must bear an Omniscience-Aspect, with this requirement holding for all of the other aspects of omnipotence noted above as well. Importantly, however, in the 'exercising' of these aspects, God would also have a number of accidental aspects, three of which will be the following:

(25) (Accidental Aspects) (a) Creator-Aspect: Omnipotence ${ }_{y}[y$ is creator] (i.e. Omnipotence insofar as it is the performance of the action of creating the universe (i.e. Creator))

(b) Moral Lawgiver-Aspect: Goodness ${ }_{y}[y$ is moral $]$ (i.e. Omnipotence insofar as it the ability to perform the best action/kind of action, many good actions and no bad actions insofar as it is performance of the action of revealing the moral law (i.e. Moral Law Giver))

(c) Particular Knowledge-Aspect: Omniscience ${ }_{y}[y$ is p-knowledge $]$ (i.e. Omnipotence insofar as it the ability to know of all true proposition and believe no false propositions insofar as it is the knowing of the truth value of a certain proposition (i.e. Particular Knowledge))

For (Accidental Aspects), God bears certain aspects that qualitatively differ, yet are numerically identical to him (and all of his other aspects). However, as these aspects do not make God what he is - they do not make him divine- they are accidental aspects of God and thus can be lacked by him-without him ceasing to be what he is. For heuristic purposes, we can illustrate the various distinctions made within the essentialist aspectival framework in this specific context as follows (with all the relations remaining as before and now 'Creator' standing for 'Creator-Aspect', 'Omniscience' standing for 'Omniscience-Aspect', 'Omnipresence' standing for 'Omnipresence-Aspect', 'P-Knowledge' standing for 'Particular Knowledge-Aspect', 'Freedom' standing for 'Freedom-Aspect', 'Goodness' standing for 'Goodness-Aspect', 'Moral LG' standing for 'Moral Lawgiver-Aspect') (Fig. 4): 


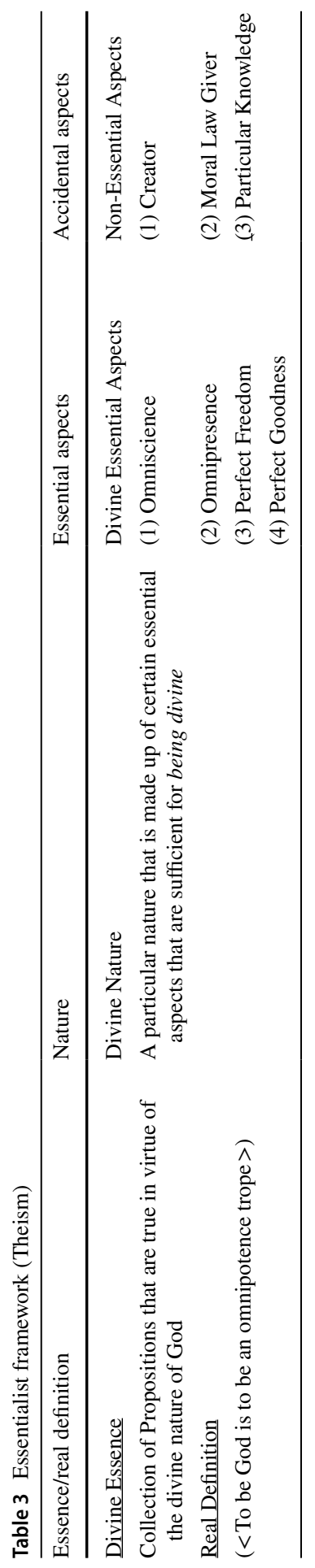




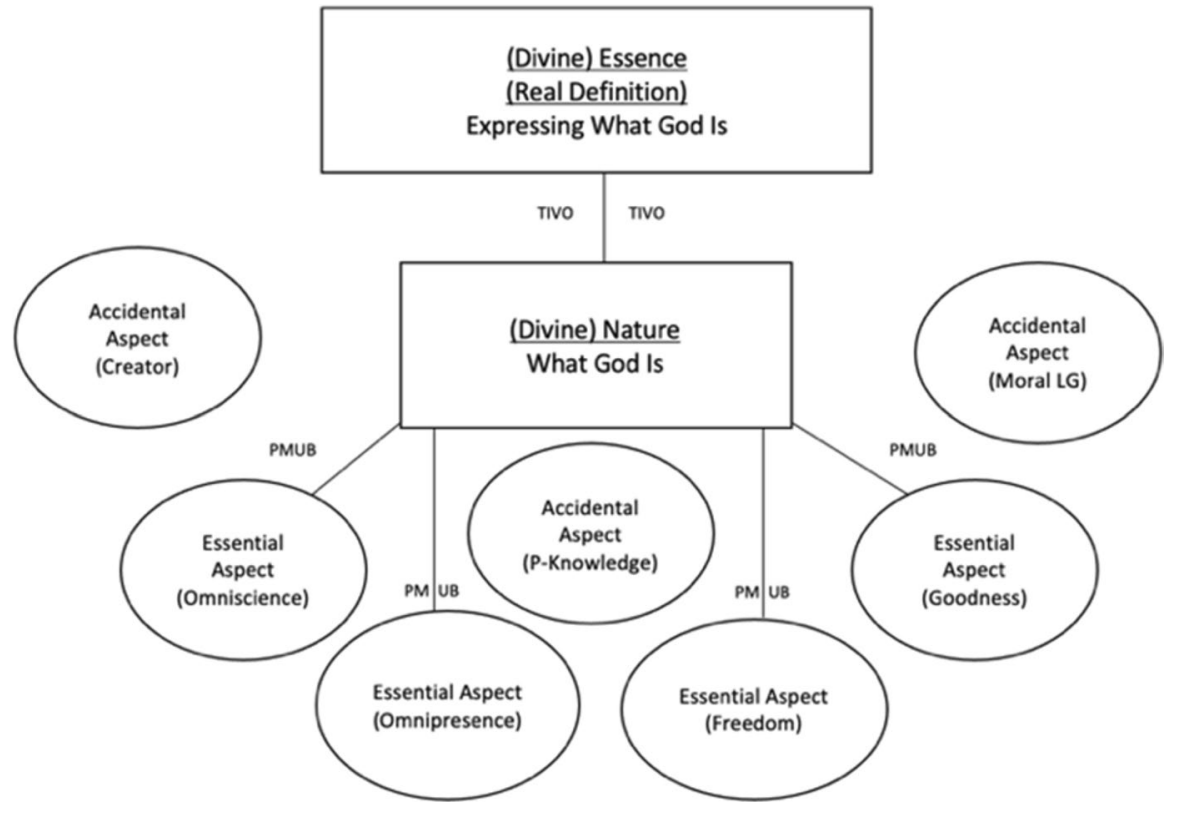

Fig. 4 Essentialist framework (theism)

As in the more mundane case of David above, in this illustration, we see that the essential aspects of God are connected to his nature and thus his essence. In contrast, the accidental aspects of God do not have a connection to his nature and thus his essence. In other words, it is the essential aspects of God, and not his accidental aspects, that play a role in defining him as he is - through making up God's nature, which his essence (or real definition) is true in virtue of. However, in this specific theistic case, unlike in the more mundane case, we have multiple essential aspects and accidental aspects being borne by God, rather than any essential or accidental properties being exemplified by him-which thus retains God's simplicity (i.e. his lack of metaphysical complexity).

Now, focusing again on the accidental aspects of omnipotence, for (a), we have an 'aspect', and for (b)-(c) we have two 'sub-aspects'-which, as noted previously, are aspects of aspects. More precisely, and taking these individually, with (a) we have a statement concerning a particular way in which the omnipotence-trope is exercised-specifically, it is the particular action performed by the omnipotence-trope in creating the universe. Whereas, in the case of (b), what we have is that of the omnipotence-trope fulfilling the role had by the Goodness-Aspect by performing the best action/kind of action of providing a certain moral law (e.g. the Ten Commandments) to a specific people groupthe latter is thus a sub-aspect of the Goodness-Aspect. And in the case of (c), what we have is that of the omnipotence-trope fulfilling the role had by the Omniscience-Aspect of knowing the truth value of a certain proposition - the latter is thus a sub-aspect of the Omniscience-Aspect. In each of these cases — aspect and sub-aspect-we have the positing of accidents in the divine life. Which provides the grounds for dealing with (A10) of 
the Aloneness Argument as follows: this specific premise takes it to be the case that God cannot have any accidents-as supposedly the DDS requires God to lack accidents, due to the fact that God's identity to an accident would render him as contingent. However, against this, the Aspectival Account allows one to affirm the identity between God and his attributes — construed as aspects-whilst allowing them to bear differing qualities to him. Thus God can have accidents (i.e. accidental aspects) without falling into absurdity. That is, as these accidents are aspects - rather than properties - they can qualitatively differ from the omnipotence-trope (and one another) by bearing further 'qualities' (i.e. 'qualitied' sub-aspects) that the omnipotence-trope (and each of the other aspects) does not have. So, in the case under question, we have the following being true ${ }^{22}$ :

The primary reason in support of the truth of (26) and (27) is two-fold: first, as Leibniz's Law is silent in regards to aspects (as this law solely applies to complete individuals and thus does not generalise over to the (essential and accidental) aspects of omnipotence, which exist as incomplete/dependent entities), if Omniscience ${ }_{y}[y$ is p-knowledge $]$ is contingent - through the proposition that is known by God being a contingent truth - there is no requirement that Omnipotence (unqualified) must also be contingent in order for both of these entities to be numerically identical. Rather, the silence of Leibniz's Law allows the former to have this quality, which is, in turn, lacked by the latter. Second, in building on the first point, we can thus hold to (Block) being true within an aspectival context, as it doesn't follow from the fact that an aspect of an individual has a certain quality that the individual that bears that aspect also has that quality - as in our previous example, $\operatorname{David}_{y}[y$ is a philosopher] does not want to go on a camping trip does not entail 'David does not want to go on a camping trip'. Similarly, in the theistic case under question, Omniscience $y$ [ $y$ is p-knowledge] has the quality of being contingent — as it can be lacked by God, without causing him to cease to be God. However, 'Omnipotence (unqualified)' does not have the quality of being contingent, as it has the quality of being necessary — as God must exist in order to be God. So, the statements 'Omnipotence (unqualified) is not contingent (i.e. is necessary)' and 'Omniscience ${ }_{y}[y$ is p-knowledge $]$ is contingent' are what is true, which shows that aspects of God (i.e. Omnipotence) can have qualities which God unqualified does not have. Therefore, what have within this aspectival framework is that of God being able to have an intrinsic accident — based on divine freedom, the contingency of creation and divine omniscience in the alone world (and other worlds) — whilst still being identical to this accident, without; however, this identity rendering God as a contingent entity-due to the fact that God bears multiple essential and accidental aspects that are qualitatively different, yet numerically identical to him (and each other). One of these (sub)aspects-which has been termed Omniscience $[y$ is p-knowledge $]$ - focuses on God's contingent knowledge about the truth value of a certain proposition-specifically, that of him possessing knowledge

\footnotetext{
${ }^{22}$ The 'quality' of necessity in (26) would be an aspect of omnipotence: Necessity-Aspect (i.e. Omnipotence ${ }_{y}[y$ is necessary $]$ ), and the 'quality' of contingency in (27) would be a sub-aspect of the P-Knowledge-Aspect (i.e. P-Knowledge $y$ [ $y$ is contingent $]$ ).
} 
concerning the contingency of creation (i.e. him having created a non-God world or not) and his aloneness or accompaniment (i.e. him being alone or with other non-God things, based upon his creative action) in each of the worlds in which he exists. This aspect is identical to God and contingent, yet as this entity is an incomplete entity, and thus Leibniz Law does not include it within its domain, this quality of contingency does not render God as contingent himself. Rather it is this aspect, which is a positive (intrinsic) ontological feature of God, and not God (unqualified) who has this quality, with the latter simply remaining as a necessary being. Thus, contra (A10), if the DDS is true - as formulated by the Aspectival AccountGod can have accidents (which are intrinsic features of him), whilst remaining simple and necessary, and thus the Accidents Assumption and (most importantly) the Aloneness Argument that rests upon this assumption, is indeed false. ${ }^{23}$

Yet, we do not need to end on a negative note, as in the case of the defeat of the Aloneness Argument within an aspectival framework, a Classical Theist is provided with good reason to modify the classical conception of the DDS found in (1) in such a way as to not negate things of God which he, in fact, can indeed possess. This proposed revision, though minor, is indeed important and can be construed as follows:

(28) (Divine Simplicity *) There is no metaphysical or physical composition in God, such that:

(i) There is no distinction in God between substance/attribute properties, essence/existence, form/matter, act/potency, genus/ differentia, agent/ action, and essence/accidental properties

(ii) All of God's intrinsic features are identical not only to each other but to God Himself

As before, the DDS negates all metaphysical complexity within God; however, unlike before, this negation, in respect to accidents, would solely be that of accidental properties, which allows God to indeed possess accidents that are "propertylike'-namely, accidental aspects, that are nevertheless not numerically distinct intrinsic features. God can thus have accidents, yet remain simple and necessary, in an alone world or a world with other, non-God things.

\footnotetext{
23 Interestingly, the conclusion reached here also allows one to deal with the (infamous) modal collapse argument, stated most recently by Mullins (2021, 94-95) as such:

M1 If God intentionally acts to actualize this world, then this world cannot possibly fail to obtain.

M2 If God's intentional act to actualize this world is absolutely necessary, then this world exists of absolute necessity.

M3 God's existence is absolutely necessary.

M4 Anything that is identical to God's existence must be absolutely necessary.

M5 All of God's intentional actions are identical to each other such that there is only one divine act.

M6 God's one divine act is identical to God's existence.

M7 God's one divine act is absolutely necessary. (M3-M6).

M8 God's intentional act to actualize this world is absolutely necessary. (M7).

M9 This world exists of absolute necessity. (M2, M8).

This argument can be avoided within the framework and account that has been proposed here, as (M4) is indeed false, given that God's creative act-construed in the Aspectival Account as the CreatorAspect- $i s$ identical to God, yet it can qualitatively differ from him, and thus God (unqualified) can be necessary whilst this aspect (i.e. his creative act) and the world both remain contingent.
} 


\section{Conclusion}

In conclusion, the issue presented to the Classical Theist by the Aloneness Argument-namely, the falsity of the DDS—has been shown to be a non-issue, given that one of the key premises of the argument-which expresses the "Accidents Assumption'-is itself false once the DDS is explicated within an essentialist aspectival framework. The DDS, as construed through the Aspectival Account, allows a Classical Theist to conceive of God as having accidents, without, however, them falling into absurdity and facing the dilemma presented by the Aloneness Argument. The God of Classical Theism can indeed bear accidents (i.e. accidental aspects) and yet still be simple and a necessary entity in every alone or accompanied world. ${ }^{24}$

\section{Declarations}

Conflict of interest The authors declare that they have no conflict of interest.

\section{References}

Baxter, D. L. M. (1999). The discernibility of identicals. Journal of Philosophical Research, 24, 37-55. https://doi.org/10.5840/jpr_1999_16

Baxter, D. L. M. (2016). Aspects and the alteration of temporal simples. Manuscrito, 39, 169-181. https://doi.org/10.1590/0100-6045.2016.V39N4.DB

Baxter, D. L. M. (2018a). Self-differing, aspects, and Leibniz's law. Noûs, 52, 900-920. https://doi.org/ 10.1111/nous. 12199

Baxter, D. L. M. (2018b). Oneness, aspects, and the neo-confucians. In P. Ivanhoe, O. Flanagan, V. Harrison, H. Sarkissian, \& E. Schwitzgebel (Eds.), The oneness hypothesis: Beyond the boundary of self (pp. 90-105). Columbia University Press.

Cooper, J.W. (2006). Panentheism: The other god of the philosophers. Baker Academic

Dolezal. J. (2011) God without parts. Pickwick Publications.

Fine, K. (1994a). Essence and modality: the second philosophical perspectives lecture. Philosophical Perspectives, 8, 1-16. https://doi.org/10.2307/2214160

Fine, K. (1994). Senses of essence. In W. Sinnott-Armstrong, D. Raffman, \& N. Asher (Eds.), Modality, morality and belief. Essays in honor of Ruth Barcan Marcus (pp. 53-73). Cambridge University Press.

Fine, K. (1995). Ontological dependence. Proceedings of the Aristotelian Society, 95, 269-290. https:// doi.org/10.1093/aristotelian/95.1.269

Giannotti, J. (2019). The identity theory of powers revised. Erkenntnis, 86, 603-621. https://doi.org/10. 1007/s10670-019-00122-5.

Heil, J. (2012). The universe as we find it. Oxford University Press.

Kärkkäinen, V. (2017). The doctrine of god: A global introduction. 2nd ed. Baker Academic.

Lowe, E.J. (2006). The four category ontology. Oxford University Press.

Mullins, R.T. (2021). Classical theism. In Arcadi, J.M \& Turner, J.T (eds.) T\&T Clark Handbook of Analytic Theology (pp. 85-100). T\&T Clark

Schmid, J. C., \& Mullins, R. T. (2021). The aloneness argument against classical theism. Religious Studies. https://doi.org/10.1017/S0034412520000554

Sider, T. (2007). Parthood. Philosophical Review, 116, 51-91. https://doi.org/10.1215/00318 108-2006-022

${ }^{24}$ Competing interests: The author declares none. 
Sijuwade, J. (2021). Divine simplicity: The aspectival account. European Journal for Philosophy of Religion, 1-37. https://doi.org/10.24204/ejpr.2021.3306

Swinburne, R. (2010). Is there a God? Oxford University Press.

Swinburne, R. (2016). Coherence of theism. 2nd ed. Oxford University Press.

Turner, J. (2014). Donald Baxter's composition as identity. In D. Baxter \& A. Cotnoir (Eds.), Composition as Identity (pp. 225-243). Oxford University Press.

Publisher's Note Springer Nature remains neutral with regard to jurisdictional claims in published maps and institutional affiliations. 